\title{
Influenza vaccination uptake among Iranian Older Adults: Application of the Health Belief Model
}

\author{
Mohammad ali Morowatisharifabad ${ }^{1}$, Zahra Aalipour ${ }^{2}$, Sara Jambarsang ${ }^{1}$, Masoumeh \\ Abbasi-Shavazi $^{3}$, and Masuda Mojahed ${ }^{4}$ \\ ${ }^{1}$ Shahid Sadoughi University of Medical Sciences and Health Services \\ ${ }^{2}$ Affiliation not available \\ ${ }^{3}$ School of Public Health, Shahid Sadoughi University of Medical Sciences, \\ ${ }^{4}$ School of Medicine, Shahid Sadoughi University of Medical Sciences
}

July 8, 2020

\begin{abstract}
Background: Influenza is an acute respiratory viral infection that can induce severe complications, hospitalization, and even death among older adults. Seasonal influenza vaccination has proposed for its prevention. The aim of this study was to determine the related factors of influenza vaccination among Iranian Older Adults in 2018 based on Health Belief Model. Methods: In this cross-sectional study, 206 participants aged 65 years and over were examined. The data collection tool was a questionnaire based on Health Belief Model constructs. The logistic regression model was used for data analysis. Results: Only $24.3 \%$ of the participants had been seasonally vaccinated, over the past year, and $58.3 \%$ had received at least one dose of seasonal flu vaccine from the age of 65 . Cues to action $(\mathrm{OR}=1.52, \mathrm{P}$-value=0.002), Knowledge $(\mathrm{OR}=1.27$, $\mathrm{P}$-value $=0.020)$, and Perceived Susceptibility $(\mathrm{OR}=1.18, \mathrm{P}$-value $=0.007)$ were statistically significant predictors of seasonal influenza vaccination. Conclusion: The cues to action stood as the strongest predictor of seasonal influenza vaccination, which should be addressed in health promotion intervention programs in the elderly.
\end{abstract}

\section{Hosted file}

Aali pour990305 (3asian journal) (7).docx available at https://authorea.com/users/340890/ articles/468033-influenza-vaccination-uptake-among-iranian-older-adults-application-ofthe-health-belief-model 